\title{
Phase Transition in Superconducting Thin Films of Tl System Employing a One-Zone Furnace and Deposited by Spray Pyrolysis
}

\author{
Jorge Luis Rosas-Mendoza ${ }^{1,2}$, L. Perez-Arrieta ${ }^{3}$, Miguel Aguilar-Frutis ${ }^{1 *}$, Ciro Falcony ${ }^{4}$, \\ R. Vázquez-Arreguín ${ }^{1}$, Alejandro Miguel Rosas-Mendoza ${ }^{1}$
}

${ }^{1}$ Centro de Investigación en Ciencia Aplicada y Tecnología Avanzada, Instituto Politécnico Nacional, México D.F., México; ${ }^{2}$ Unidad Profesional Interdisciplinaria de Biotecnología, Instituto Politécnico Nacional, México D.F., México; ${ }^{3}$ Unidad Académica de Física, Universidad Autónoma de Zacatecas (UAZ), Zacatecas, México; ${ }^{4}$ Departamento de Física, Centro de Investigación de Estudios Avanzados (CINVESTAV-IPN), México D.F., México.

Email: *mafrutis@yahoo.es

Received September $4^{\text {th }}, 2013$; revised October $16^{\text {th }}, 2013$; accepted October $30^{\text {th }}, 2013$

Copyright (C) 2013 Jorge Luis Rosas-Mendoza et al. This is an open access article distributed under the Creative Commons Attribution License, which permits unrestricted use, distribution, and reproduction in any medium, provided the original work is properly cited.

\begin{abstract}
A study of the phase transitions in superconducting thin films of the Thallium-Barium-Calcium-Copper (TBCCO) system is carried out. In particular, it was got the Tl-1223 phase. For this purpose, and using the ultrasonic spray pyrolysis technique, Barium-Calcium-Copper precursor films were first obtained. Upon deposition of the precursor films, and as a second step, they were thallium (Tl) diffused in the one-zone furnace at $860^{\circ} \mathrm{C}$. This methodology resulted in superconducting films that showed a phase transition as follows: Tl-2223 $\rightarrow$ Tl-2223 $+\mathrm{Tl}-2212 \rightarrow \mathrm{Tl}-2212 \rightarrow \mathrm{Tl}-1223$, achieved between 2 and 7 hours of thallium diffusion. The evidence of the phase transitions was corroborated by the experimental results of X-ray diffraction, energy dispersive spectroscopy and resistance-temperature measurements.
\end{abstract}

Keywords: Superconductors; Thin Films; Ultrasonic Spray Pyrolysis

\section{Introduction}

Recently, thin films of high Tc superconducting oxides have attracted much attention due to their unique physical characteristics and its potential for application in the near future. The applications of high Tc superconductors (in thin film or bulk) are in microelectronics, in power systems, in high current systems, in storage systems of superconducting magnetic energy, and in others [1-6]. Among general processes for the preparation of high Tc superconducting thin film are sputtering [7], pulsed laser ablation [8], chemical vapor deposition, organic metal [9], the molecular beam epitaxy [10], sol-gel [11], and others. In general, processes for preparing superconducting thin films by using a vacuum system maintenance are expensive and complex in operation. Reports on the preparation of superconducting TBCCO system using the spray pyrolysis technique have also been made $[12,13]$. The great advantages of the process of this deposition technique include its simplicity, high deposition rate, large

${ }^{*}$ Corresponding author. storage area, controlled chemical composition and low cost. A job of interest is the phase obtaining thallium thin film 1223 using a single zone furnace. The Tl-1223 phase is of considerable importance because it has, on the other phases, the highest critical current density outside and inside strong external magnetic fields [14]. Coupled with this, obtaining the same in most simple and direct stages is always advisable as its synthesis in the furnace area. The methodology involved in the two-zone furnace includes the preparation of a precursor film and after the addition of thallium in the latter. For this, last step two temperatures should be considered optimal: the precursor film and the source of thallium. Furthermore, one should consider optimal distance between source precursor film and thallium, since thallium gas and oxygen gas must be transported along this distance to reach the precursor film and incorporated within it thus forming the superconducting phase Tl-1223 the film [15]. For this reason, the service work is to obtain this phase in the furnace zone, a way to avoid the inherent complexities prevailing in the two-zone furnace. The preparation of 
some bulk superconductors has already been completed in the furnace a zone $[16,17]$. However, as far as it is consulted, it has not been reported obtaining thin films of Tl-1223 system on a one zone oven, nor undertaken a systematic study of the superconductor(s) phase(s) in this system (zone oven). This research paper presents results of both the phase transition and superconducting thin films of Tl-1223 phase TBCCO system. The superconducting films were obtained by the two-step method. The formation of a precursor film was achieved first by ultrasonic spray pyrolysis, and after the diffusion of thallium, as a second step, we obtained the superconducting film. It was found that the phase transition is as follows: $\mathrm{Tl}-2223 \rightarrow \mathrm{Tl}-2223+\mathrm{Tl}-2212 \rightarrow \mathrm{Tl}-2212 \rightarrow \mathrm{Tl}-1223$, and occurs between 2 and 7 hours after the start of the diffusion.

\section{Experimental Details}

Superconducting films were synthesized by the two step process. In the first stage, the precursor films with stoichiometry $\mathrm{Ba}_{2} \mathrm{Ca}_{2} \mathrm{Cu}_{3}$ were deposited by spray pyrolysis ultrasonic technique using a solution of acetylacetonates $0.006 \mathrm{M}$ of $\mathrm{Ba}, \mathrm{Ca}, \mathrm{Cu}$ (2, 4-pentanedionates) dissolved in $\mathrm{N}, \mathrm{N}$-dimethylformamide (N,N-DMF). The substrates consisted of silver plates Goodfellow (99.9\%) with dimensions $10 \mathrm{~mm} \times 5 \mathrm{~mm}$, and $0.25 \mathrm{~mm}$ thick. These substrates were polished mechanically with a suspension of diamond-shaped grains with size from $1.0 \mu \mathrm{m}$ to 0.1 $\mu \mathrm{m}$. The ultrasonic spray pyrolysis system has been used for synthesis of films. This is basically a spray tank (obtained from ultrasonic pulses) of a solution made from the source material of interest on the hot substrate. As the carrier gas may be used air, oxygen, etc. At adequate pressure [18]. Commercial ultrasonic humidifier operating at $750 \mathrm{KHz}$, is used in this work to generate the aerosol solution. Additionally, air was used as carrier gas at a flow rate of $5.0 \mathrm{l} / \mathrm{min}$. The deposition time of the precursor films was 60 minutes at $565^{\circ} \mathrm{C}$. The thallium diffusion process was conducted in a single zone furnace using a chamber consisting of a quartz tube of high purity of $61 \mathrm{~cm}$ long and $4 \mathrm{~cm}$ in diameter. The thallium source consisted of a tablet with 0.1 grams of $\mathrm{Tl}_{2} \mathrm{O}_{3}+$ 0.42 grams of $\mathrm{BaCuO}_{2}+0.17$ grams of $\mathrm{Ca}_{2} \mathrm{CuO}_{3}$. The tablet and closely precursor film were placed and enclosed in a bag of silver, and the latter inserted into a pot of alumina in the middle of the oven. The furnace was brought to a temperature of $860^{\circ} \mathrm{C}$ (thalliumnization temperature) at a heating rate of $300^{\circ} \mathrm{C} / \mathrm{h}$. Temperature of $860^{\circ} \mathrm{C}$ was maintained for $2,5,6,7$ and $8 \mathrm{hrs}$ and then allowed to cool to room temperature. During the process of diffusion of $\mathrm{Tl}$, a flow of high purity oxygen $\left(\mathrm{O}_{2}\right)$ was allowed to pass at a speed of $0.5 \mathrm{~cm}^{3} / \mathrm{min}$ through the furnace chamber. The microstructure of the films are characterized by scanning electron microscope JEOL,
JSM-6300, equipped with an EDS system, JED-2300T to observe the surface morphology and chemical composition estimate both precursor films and films thallinated with thallium or broadcast. The crystalline structure of the films was evaluated by X-ray diffraction using a Siemens D-5000 diffractometer $(\mathrm{Cu} \mathrm{K} \alpha, 0.15406 \mathrm{~nm})$. The indexing of the diffraction peaks, and the ratio of the phases was assessed using the MATCH program [19]. The characterization of the critical temperature (Tc), was performed with the technique of the four points, using a constant current of $100 \mathrm{~mA}$. Finally, the average roughness of the superconducting films was measured with a profilometer Veeco, Dektak ${ }^{3}$ model.

\section{Results}

Representative morphology obtained by SEM of the precursor films that shown in Figure 1. The chemical composition analysis estimates the following stoichiometry: $\mathrm{Ba}=22.14 \%$ at., $\mathrm{Ca}=29.63 \%$ at. and $\mathrm{Cu}=48.33 \%$ at. Based on the ideal composition of the films $(30 \%$ at. $\mathrm{Ba}, 30 \%$ at. $\mathrm{Ca}$ and $40 \%$ at. of $\mathrm{Cu}$ ) we can see that these films are rich in $\mathrm{Cu}$ and poor in $\mathrm{Ba}$. However, previous work has shown that this film precursor composition may be sufficient to obtain superconducting films of Tl-1223 phase in the two-zone furnace and with high values of Tc [20]. Both the morphology and the composition of the precursor films are of great importance since strongly influence the composition and characteristics of superconducting films final broadcast thallium [20]. Thallium diffusion was performed on average $\sim 860^{\circ} \mathrm{C}\left(858.7^{\circ} \mathrm{C}\right.$ $860.7^{\circ} \mathrm{C}$ ), and duration times of 2, 5, 6, 7 and $8 \mathrm{hrs}$. After the diffusion treatment of thallium in precursor thin films, they were analyzed by diffraction $r X$, Figure 2 . Shows that after treatment of 2 hours, the sample P1 shows phase $\mathrm{Tl}-2223$, which is stable because the presence of mixed phases is almost zero, the highest num-

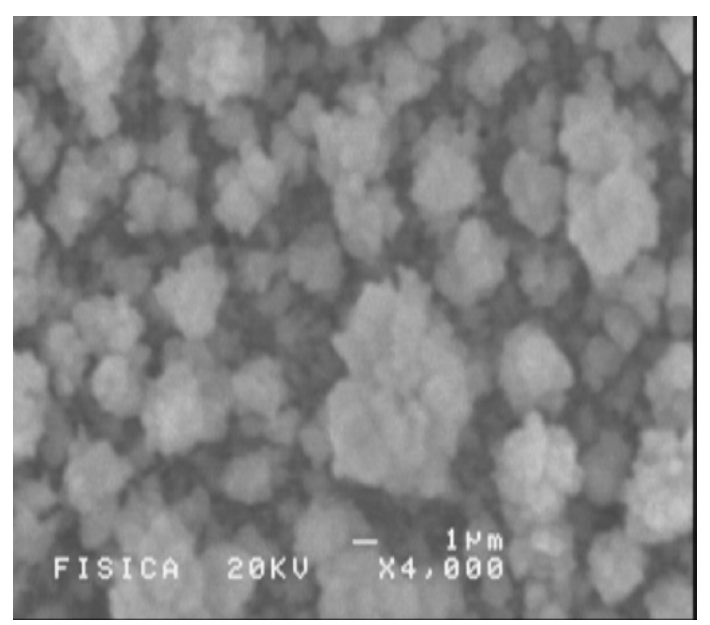

Figure 1. Representative morphology of the precursor samples. 


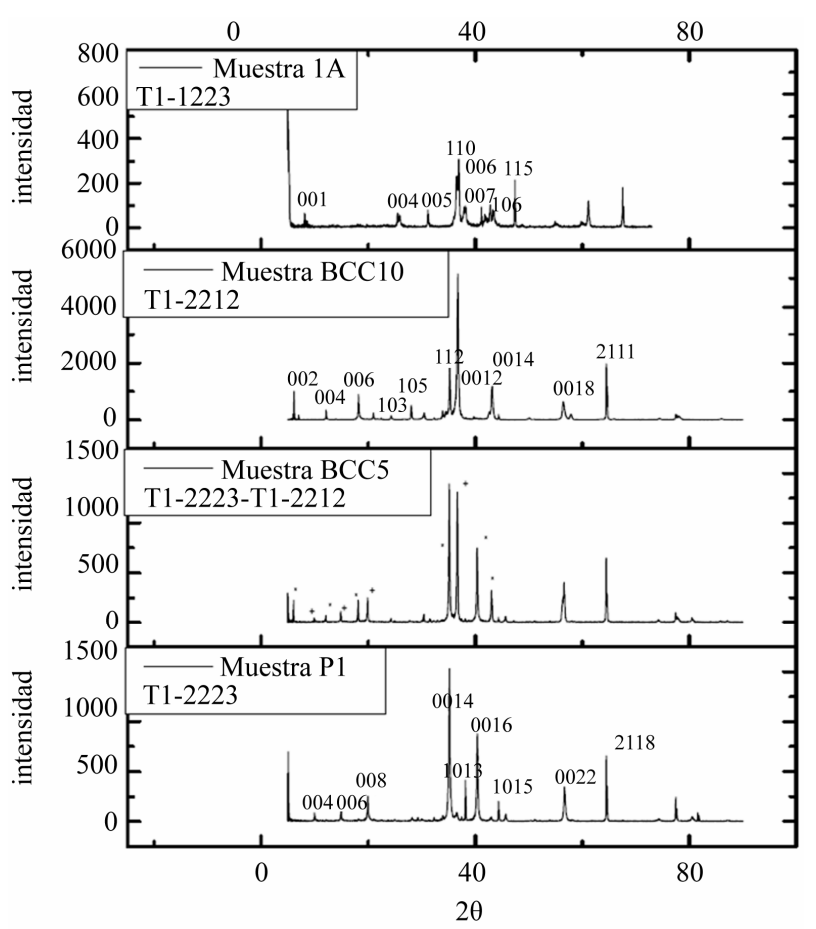

Figure 2. X-Ray spectra. Samples P1 phase Tl-2223, sample BCC5 phase Tl-2223 (+)-Tl-2212 (*), sample BCC10 phase Tl-2212, sample 1 A phase Tl-1223.

ber of diffraction peaks corresponding to the Tl-2223 phase.

The phase identification was corroborated with JCPDS card 000411334 . Unindexed peaks are from the substrate. BCC5 sample, which had a 5-hour treatment, shows a diffractogram consistent with a mixed phase composed of the phase Tl-2212 and Tl-2223, showing a greater presence second phase (Tl-2223). The presence of secondary phases is negligible. Moreover, with 6 hours of treatment observed in the diffraction pattern of the sample BCC10 Tl-2212 phase in stable form and no trace of Tl-2223 phase. Finally, it is observed that after 7 hours of diffusion thallium (diffractogram of sample 1A) displays the phase of Tl-1223 almost stably and without the presence of secondary phases. At 8 hours of treatment the sample has a significant thinning it impossible to visualize the presence of phases in the diffractogram. The chemical composition of the samples is presented in Table 1. The table we observe that the samples: P1 (heat treated 2 hours and Tl-2223 phase), the sample $\mathrm{BCC} 10$ (6 hours treatment phase Tl-2212) and sample 1A (7hour treatment phase and Tl-1223) have chemical compositions that are similar to the theoretical composition of each phase. Also be observed for the sample X, because it was very thin, the amount of thallium is showed lower. The first three samples have shorter times of 8 hours, the sample which has less $\mathrm{Tl}$ is 1a, which shows the phase Tl-1223 and having more amount of the sample
Table 1. Chemical composition of thallinated samples in 2,5 , 6, 7 and 8 hrs.

\begin{tabular}{|c|c|c|c|c|c|c|}
\hline \multirow[t]{2}{*}{ Sample } & \multirow{2}{*}{$\begin{array}{c}\text { Time of } \\
\text { Thallination } \\
\text { (hrs) }\end{array}$} & \multicolumn{5}{|c|}{$\begin{array}{c}\text { Chemical composition } \\
\% \text { atomic }\end{array}$} \\
\hline & & Phase & $\mathrm{Tl}$ & $\mathrm{Ba}$ & $\mathrm{Ca}$ & $\mathrm{Cu}$ \\
\hline P1 & 2 & Tl-2223 & 22.65 & 21.39 & 24.42 & 31.52 \\
\hline BCC5 & 5 & $\begin{array}{l}\text { Tl-2223 } \\
\text { Tl-2212 }\end{array}$ & 25.96 & 22.34 & 23.78 & 27.91 \\
\hline BCC10 & 6 & Tl-2212 & 26.90 & 22.40 & 15.29 & 35.29 \\
\hline $1 \mathrm{~A}$ & 7 & Tl-1223 & 11.02 & 20.21 & 32.42 & 36.65 \\
\hline $\mathrm{X}$ & 8 & - & 8.64 & 19.23 & 28.07 & 44.06 \\
\hline \multirow{3}{*}{$\begin{array}{l}\text { Ideal } \\
\text { composition }\end{array}$} & & Tl-2223 & 22.2 & 22.2 & 22.2 & 33.4 \\
\hline & & Tl-2212 & 28.57 & 28.57 & 14.28 & 28.57 \\
\hline & & Tl-1223 & 12.5 & 25.0 & 25.0 & 37.5 \\
\hline
\end{tabular}

is BCC5 Tl, which has the mixed phase Tl-2223-Tl-2212. Also observed that the diffusion time for the amount of thallium in the samples increases gradually as the transition occurs phases: 2 hours, $\mathrm{Tl}-2223$ phase $(\%$ at. of $\mathrm{Tl}=$ 22.65), 5 hours, phase Tl-2212-Tl-2223, ( $\%$ at. of $\mathrm{Tl}=$ $25.96)$, and 6 hours $\mathrm{Tl}-2212$ phase $(\%$ at. of $\mathrm{Tl}=26.90)$. However, until 7 hours, there is a reduction, Tl-1223 phase $(\%$ at. of $\mathrm{Tl}=11.02)$.

The morphologies of the samples P1 (2 hours of treatment) and BCC5 (5 hours of treatment), are both similar, showing platelets not defined in shape, their borders are seen not so marked because they have a certain cast, plus some training appears sub-grains at the surface of BCC5. For sample BCC10 (6 hours treatment) shows a morphology with a higher melt (platelets are not seen), but more sub-grains on the molten surface can be seen, finally the specimen A1 (Treatment 7 hours), shows platelet morphology with grain boundaries more marked than those observed in the P1 and BCC5 samples. The morphology of the sample with X, with 8 hours of treatment, lost shape and observed platelet shape grains without it seems that material has a higher level of melt relative to those with the above samples. The $\mathrm{R}$ vs. $\mathrm{T}$ curve is shown in Figure 3, which gave values of about $110 \mathrm{~K}$ TC for sample $\mathrm{P} 1$, of $99 \mathrm{~K}$ for the sample BCC5, for sample $96 \mathrm{~K}$ and $100 \mathrm{~K}$ for BCC10 Sample 1A corresponding with those reported for these phases of the family of thallium. Finally, Table 2 summarizes the values of Tc obtained in this work and the values obtained by other groups, demonstrating that the Tc values obtained in this study are comparable to the one obtained by other research groups. Table 2 lists values of roughness that are present in the samples.

\section{Discussion}

The identification of the phases 2223, 2212 and 1223 of the system is achieved by comparing TBCCO diffracto- 


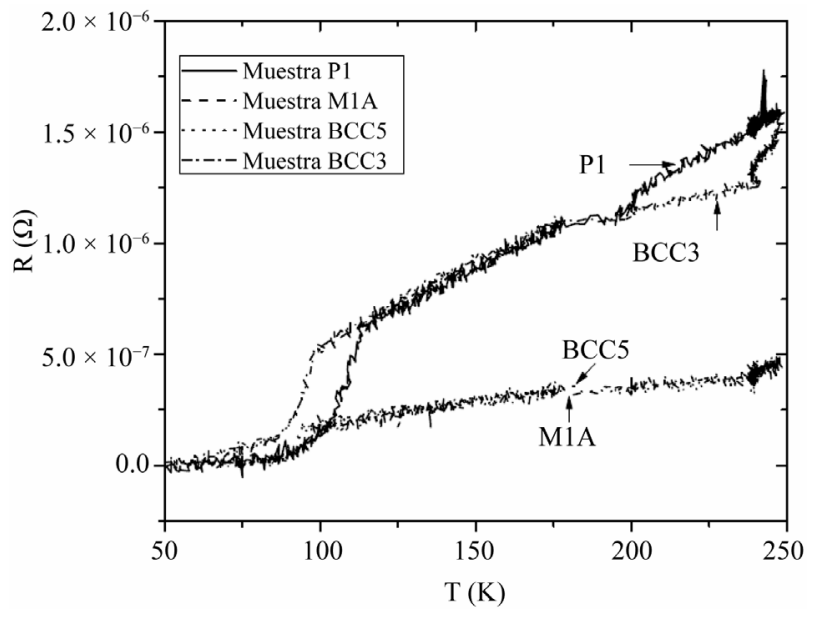

Figure 3. Figure shows the electric behavior $R$ vs $T$ of the samples: P1 (phase Tl-2223), BCC5 (Tl-2223-Tl-2212), BCC10 (Tl-2212) and $1 \mathrm{~A}$ (Tl-1223).

Table 2. Tc values, roughness, thallination time and phases of the samples obtained in this work. A comparison with Tc values obtained by other groups are shown.

\begin{tabular}{lcccc}
\hline Sample & P1 & BCC5 & BCC10 & A1 \\
\hline Phase & 2223 & 2223 & 2212 & 1223 \\
Time of diffusion of thalio & 2 & 5 & 6 & 7 \\
(hrs) & 110 & 99 & 96 & 105 \\
Tc ( ${ }^{\circ}$ K) (this job) & 5719 & 4244 & 6000 & 3435 \\
Rugosity ( $\AA$ ) (this job) & 115 & & 108 & \\
Sugise [21] Tc (K) & 107 & & 104 & \\
Aselage [22] Tc (K) & & & 106 & \\
Holstein [23] Tc (K) & & & 102 & \\
O’Connor [24] Tc (K) & & & &
\end{tabular}

grams of the samples with the letters JCPDF (Tl -2223: 000411 334, 000420352 Tl-1223, Tl-2212 000391 482) and its corresponding index is as diffractograms shown in Figure 2. Diffractograms seem check surface geometry of the films observed by scanning microscopy, because the plates simulate a c-axis orientation of the crystal structure.

Certain crystalline phases are tetragonal structures, which is in agreement with that reported in the literature, as TBCCO superconductors exhibit this structure together with one or two Tl-O layers and layers alternating perovskite $\mathrm{Ba}_{2} \mathrm{Ca}_{\mathrm{n}+1} \mathrm{Cu}_{\mathrm{n}} \mathrm{O}_{2 \mathrm{n}+1}$ and/or homologous series $\mathrm{Tl}_{\mathrm{m}} \mathrm{Ba}_{2} \mathrm{Ca}_{\mathrm{n}-1} \mathrm{Cu}_{\mathrm{n}} \mathrm{O}_{2 \mathrm{n}+\mathrm{m}+2}$ where $\mathrm{m}=1, \mathrm{n}=1-5$ are the phases of a single Tl-O layer and $\mathrm{m}=2, \mathrm{n}=1-4$ are double-layer phases of Tl-O [25]. Relative to the phase transition, it was mentioned that the volatility of thallium oxide at temperatures of forming the superconducting phase (close to $800^{\circ} \mathrm{C}$ ), is difficult to control [26]. Certain considerations between solid-vapor equilibrium be- tween thallium oxide source and the precursor film are of considerable importance. Oxide is known that $\left(\mathrm{Tl}_{2} \mathrm{O}\right)$ is the only phase of thallium oxide in gaseous form [27] and it can progress to the thallium-containing oxides such as $\mathrm{Tl}_{2} \mathrm{O}_{3}$ and $\mathrm{Tl}_{2} \mathrm{Ba}_{2} \mathrm{CaCu}_{2} \mathrm{O}_{8}$ or used to lead to the formation of latter. That is, this is an irreversible chemical reaction [28]. It has been mentioned that the Tl-2212 phase in bulk can be obtained from a precursor phase and $\mathrm{BaCuO}$ and vapor of $\mathrm{Tl}_{2} \mathrm{O}$ and $\mathrm{O}_{2}$.

For bulk materials has been found that the formation of compounds TBCCO proceeds via the reaction sequence as:

$\mathrm{Tl}(2201) \rightarrow \mathrm{Tl}(2212) \rightarrow \mathrm{Tl}(2223) \rightarrow \mathrm{Tl}(1223) \rightarrow$ $\mathrm{Tl}(1234) \rightarrow \mathrm{Tl}(1245)$ or $\mathrm{Tl}(2201) \rightarrow \mathrm{Tl}(2212) \rightarrow \mathrm{Tl}$ $(2223) \rightarrow \mathrm{Tl}$ (1212), [29]. In our case it is likely that after treatment of thallination 2 hours, the partial pressure $\mathrm{P}$ of thallium oxide $\left(\mathrm{Tl}_{2} \mathrm{O}\right)$ and thallium diffusion into the film has reached the optimum value to obtain $\mathrm{Tl}-2223$ phase in the P1 film whose composition is very close to ideal, see Table 1. The proximity of the precursor sample and the constant value of the oxygen partial pressure $\mathrm{P}$ $\left(\mathrm{O}_{2}\right)$, could lead to vapor control thallium oxide $\left(\mathrm{Tl}_{2} \mathrm{O}\right)$ during treatment and dissemination. Furthermore, the morphology of the film is presented feature of this phase (molten in certain platelet-shaped grains).

The $\%$ at. thallium, as determined by EDS in sample BCC5 indicates the presence of a larger number average thallium ( $25.96 \%$ at.), considering the combination of the phases Tl-2223 + Tl-2212. In our case, greater incorporation of thallium could have been accomplished with increased thallination time. The morphology of the sample does not change much compared BCC5 sample P1, except perhaps to the increased presence of subgrains on platelets. It seems that the nature of the sub-grains attributable to the onset of the second phase superconducting Tl-2212, as seen in the morphology of the sample $\mathrm{BCC} 10$, which has as such sub-grains are filled to a greater extent the sample, probably the Tl-2212 phase. For the latter film thallium concentration was of the order of $26.90 \%$ at., a value closest to the ideal concentration for the Tl-2212 phase.

Finally at 7 hours of thallination occurs a decrease in the amount of thallium present in the film (to a value of $11.02 \%$ at.), Resulting in phase Tl-1223. Regarding morphology reappear platelet-shaped grains, again simulating the $\mathrm{c}$ axis orientation. After passing the period of 7 hours thallination by EDS shows that the stoichiometry of the films begins to degrade, losing large amounts of thallium, probably by an erosion of the superconducting film. Figure 4(e) (Sample X), illustrates how the morphology of the film is degraded. The process seems then be one in which the precursor film goes into the superconductor at some stage during thallination with thallium, but also involves a degradation of the film, which be- 


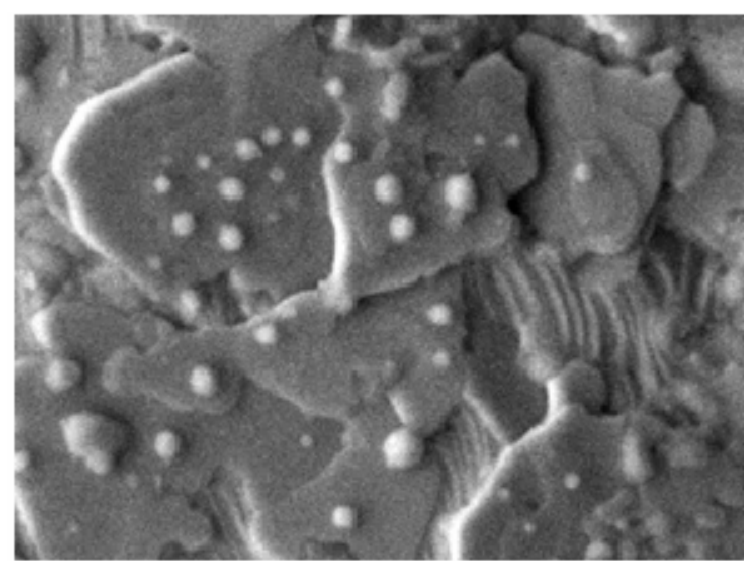

(a)

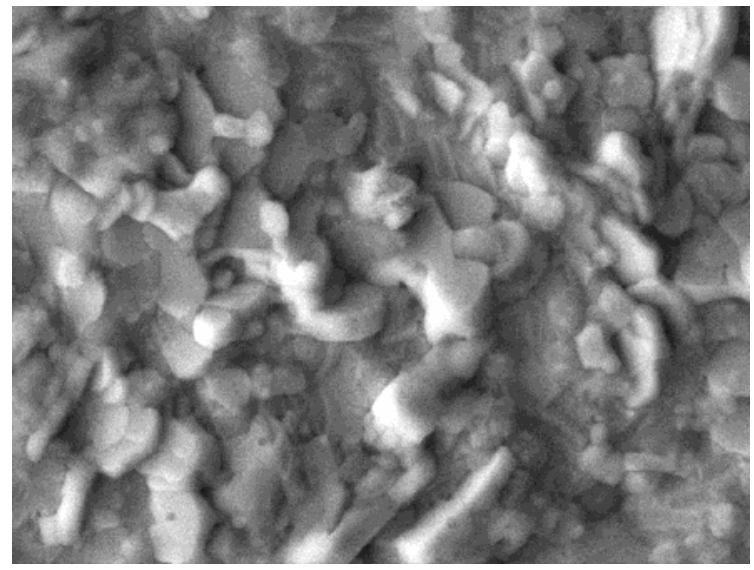

(c)

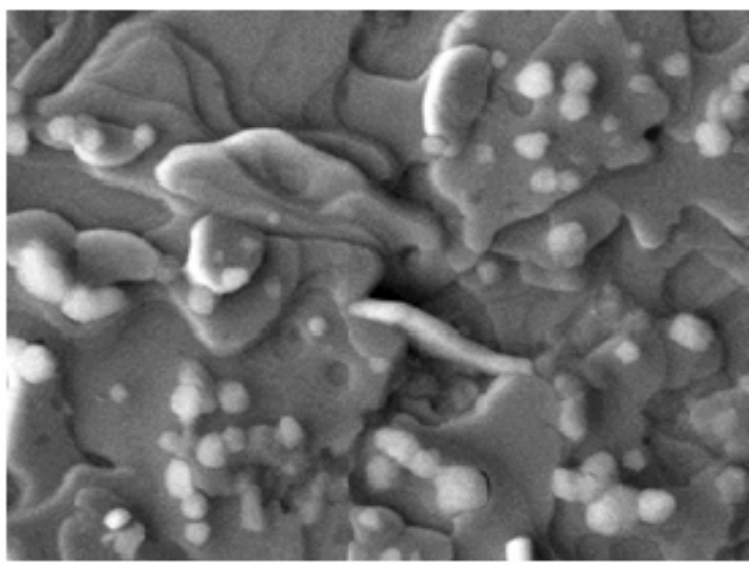

(b)

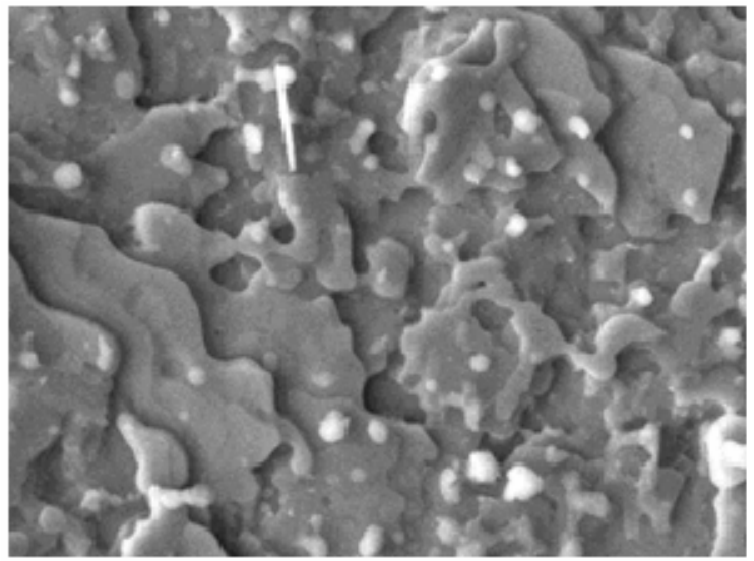

(d)

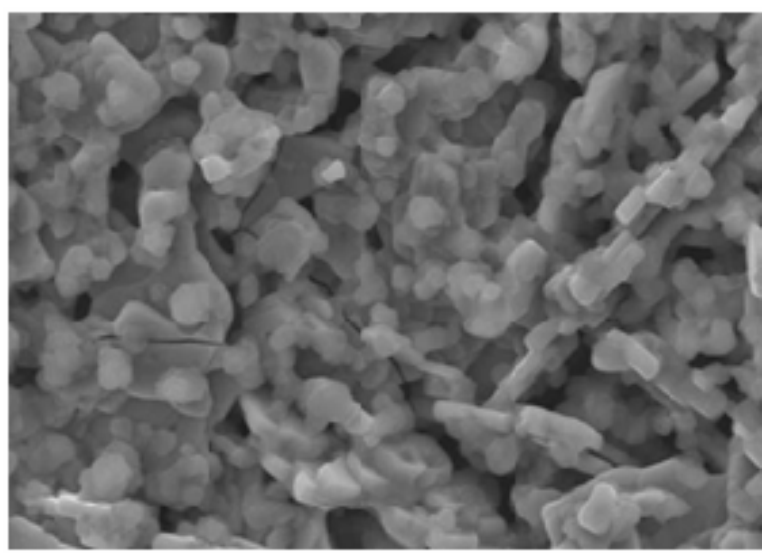

(e)

Figure 4. (a) The figure shows different morphologies that are presented in a thalinated films: 2 h (Figure 4(a) shows P1), 5 h (Figure 4(b) shows BCC5), 6 h (Figure 4(c) shows BCC10), 7 h (Figure 4(d), Sample 1A) and 8 h (Figure 4(e), Sample X), respectively; (b) The figure shows morphology for $5 \mathrm{~h}$, sample BCC5; (c) The figure shows the morphology for $7 \mathrm{~h}$, sample BCC10; (d) The figure shows the morphology of $7 \mathrm{~h}$, Sample 1A; (e) The figure shows the morphology for 8 h, Sample X.

comes visible after 7 hours of thallination, probably because of the presence of thallium or thallium vapors along with the flow of oxygen is supplied at all times of the thallination. Measurements of R vs T seem also rein- force that no correspondence with the phases present, according to their values of Tc we have of the materials in bulk: Tl-2212 $(90-110 \mathrm{~K}), \mathrm{Tl}-2223(118-125 \mathrm{~K})$ and Tl-1223 (100 - $110 \mathrm{~K})$. 
From the results of composition, microscopy, diffraction and temperature-resistance, seems to occur to obtain superconducting films has the following phase transformation route: Tl-2223 $\rightarrow$ Tl-2223 + Tl-2212 $\rightarrow$ Tl-2212 $\rightarrow$ Tl-1223, with the 7-hour period to achieve optimal phase of thallium 1223. Manufacturing routes involving superconducting thin films on one side closed crucible method [29] and on the other, the process in the two-zone furnace [30]. Using the first method and how far we have consulted, the research does not show a phase transition route, only mention under what conditions it is possible to achieve the crystalline phase Tl-2212 [31] or Tl-2223 phase [32], most of these studies agree to use thallium diffusion temperatures between 750 and $800^{\circ} \mathrm{C}$ and gas atmospheres such as $\mathrm{Ar}, \mathrm{O}_{2}$ or air. Using the second method, there have been several studies on crystalline phase growth superconducting thin films of $\mathrm{Tl}$ [33], these studies have shown that in this system there may be ireversible phase transition and Tl-2223 and Tl-2212 [34]. This research showed that the deposition technique ultrasonic spray pyrolysis can be a viable technique for the growth of superconducting thin films is also available from superconducting thin films phase Tl-2223, Tl-2212 and Tl-1223 stably by the two-step method, using a one zone furnace.

\section{Conclusion}

By spray pyrolysis, deposition technique ultrasonic test predicts the feasibility of obtaining superconducting thin films with phases: Tl-2223, Tl-2212, and Tl-1223 stably by two-step method with the use of an oven area. It was found that the diffusion of thallium and the presence of oxygen flow is the one most likely limiting the appearance of most of these phases following the transition path as Tl-2223 $\rightarrow$ Tl-2223 $+\mathrm{Tl}-2212 \rightarrow \mathrm{Tl}-2212 \rightarrow \mathrm{Tl}-1223$.

\section{Acknowledgements}

This research was made possible thanks to the research assistants, Marcela Guerrero, Ana Bertha Soto, Zachary Rivera from the Dept. of Physics at CINVESTAV-IPN and Alfonso Martinez from CICATA-IPN.

\section{REFERENCES}

[1] R. W. Simon, R. B. Hammond, S. J. Berkowitz and B. A. Willemsen, "Superconducting Microwave Filter Systems for Cellular Telephone Base Stations," Proceedings of IEEE, Vol. 92, No. 10, 2004, pp. 1585-1596. http://dx.doi.org/10.1109/JPROC.2004.833661

[2] M. S. Schmidt, R. J. Forse, R. B. Hammond, M. M. Eddy and W. L. Olson, "Measured Performance at $77 \mathrm{~K}$ of Superconducting Microstrip Resonators and Filters," IEEE Transactions on Microwave Theory and Techniques, Vol.
39, No. 9, 1991, pp. 1475-1479.

http://dx.doi.org/10.1109/22.83820

[3] H. O. Marcy, T. J. Marks and C. R. Kannewurf, "Computer Control of a Slow-AC Technique for Thermopower Measurements," IEEE Transactions on Instrumentation and Measurement, Vol. 39, No. 5, 1990, pp. 756-760. http://dx.doi.org/10.1109/19.58621

[4] P. A. Waburton, A. R. Kuzhakhmetov, C. Bell, G. Burnell, M. G. Blamire, H. Wu, C. R. M. Grovenor and H. Schneidewind, "Sub-Micron Thin Film Intrinsic Josephson Junctions," IEEE Transactions on Applied Superconductivity, Vol. 13, No. 2, 2003, pp. 821-824.

[5] H. Schneidewind and T. Stelzner, "Optimization of Surface Morphology and Electrical Parameters of Tl-Ba-Ca$\mathrm{Cu}-\mathrm{O}$ Thin Films for High Frequency Devices," IEEE Transactions on Applied Superconductivity, Vol. 13, No. 2, 2003, pp. 2762-2765.

http://dx.doi.org/10.1109/TASC.2003.811999

[6] O. S. Chana, R. Kuzhakhmetov, D. M. C. Hyland, J. Eastell, D. Dew-Hughes, C. R. M. Grovenor, Y. Koval, M. Mossle, R. Kleiner, P. Muller and P. A. Warburton, "Fabrication and Measurement of Intrinsic Josephson Junctions in Misaligned Films of $\mathrm{Tl}_{2} \mathrm{Ba}_{2} \mathrm{CaCu}_{2} \mathrm{O}_{8}$," IEEE Transactions on Applied Superconductivity, Vol. 11, No. 1, 2001, pp. 2711-2714. http://dx.doi.org/10.1109/77.919622

[7] A. H. Miklich, F. C. Wellstood, J. J. Kingston, J. Clarke, M. S. Colclough, A. H. Cardona, L. C. Bourne, W. L. Olson and M. M. Eddy, "High-T $\mathrm{c}_{\mathrm{c}}$ Thin-Film Magnetometer," IEEE Transactions on Magnetics, Vol. 27, No. 2, 1991, pp. 3219-3222.

http://dx.doi.org/10.1109/20.133896

[8] R. E. Sroxler, G. P. Rodriguez and P. N. Peters, "Field Response of Ultra-Thin Type II Superconducting Transmission Lines," IEEE Transactions on Applied Superconductivity, Vol. 4, No. 2, 1994, pp. 65-75. http://dx.doi.org/10.1109/77.291693

[9] P. L. Richards, S. Verghese, T. H. Geballe and S. R. Spielman, "The High $\mathrm{T}_{\mathrm{c}}$ Superconducting Bolometer," IEEE Transactions on Magnetics, Vol. 25, No. 2, 1989, pp. 1335-1338. http://dx.doi.org/10.1109/20.92542

[10] H. Schneidewind, M. Manzel and K. Kirsch, "2212-T1Ba-Ca-Cu-O Films on 3" Sapphire Wafers for High Frequency Filters," IEEE Transactions on Applied Superconductivity, Vol. 11, No. 1, 2001, pp. 3106-3109. http://dx.doi.org/10.1109/77.919720

[11] Kao-Cheng Huang, D. Hyland, A. Jenkins, D. Edwards and D. Dew-Hughes, "A Miniaturized Interdigital Microstrip Bandpass Filter," IEEE Transactions on Applied Superconductivity, Vol. 9, No. 2, 1999, pp. 3889-3892. http://dx.doi.org/10.1109/77.783877

[12] P. Seidel, E. Heinz, F. Schmidl, K. Zach, H. J. Kohler, H. Schneidewind, J. Borck, L. Dorrer, S. Linzen, T. Kohler, W. Michalke, M. Manzel, E. Steinbeiss, H. Bruchlos, E. B. Kley and H.-J. Fuchs, "High-T/Sub c/ Josephson Junctions and DC SQUIDs," IEEE Transactions on Applied Superconductivity, Vol. 3, No. 1, 1993, pp. 2353-2356. http://dx.doi.org/10.1109/77.233429 
[13] G. Subramanyam, F. Radpour, V. J. Kapoor and G. H. Lemon, "Fabrication and Chemical Composition of rf Magnetron Sputtered Tl-Ca-Ba-Cu-O High $T_{C}$ Superconducting Thin Films," Journal of Applied Physics, Vol. 68, 1990, p. 1157. http://dx.doi.org/10.1063/1.346711

[14] T. Venkatesan, X. Wu, A. Inam, C. C. Chang, M. S. Hegde and B. Dutta, "Laser Processing of High- $\mathrm{T}_{\mathrm{c}}$ Superconducting Thin Films," IEEE Journal of Quantum Electronics, Vol. 25, No. 11, 1989, pp. 2388-2393. http://dx.doi.org/10.1109/3.42070

[15] J. A. Ladd, B. T. Collins, J. R. Matey, J. Zhao and P. Norris, "Preparation of $\mathrm{Tl}_{2} \mathrm{Ba}_{2} \mathrm{CaCu}_{2} \mathrm{O}_{8}$ Superconducting Thin Films on $\mathrm{LaAlO}_{3}$ Substrates from MetalorganicChemical-Vapor-Deposition-Prepared Precursor Films," Applied Physics Letters, Vol. 59, No. 11, 1991, p. 1368. http://dx.doi.org/10.1063/1.105311

[16] K. E. Myers, D. W. Face, D. J. Kountz and J. P. Nestlerode, "Superconducting and Epitaxial $(\mathrm{Tl}, \mathrm{Pb}) \mathrm{Sr}_{2} \mathrm{Ca}_{1-x}$ $\mathrm{Y}_{x} \mathrm{Cu}_{2} \mathrm{O}_{7}$ Thin Films by in Situ Deposition," Applied Physics Letters, Vol. 65, 1994, p. 490. http://dx.doi.org/10.1063/1.112303

[17] A. Natarajan, W. Wang, E. Ma, R. N. Bhattacharya and R. D. Blaugher, "Magnetoresistivity Measurements of $\mathrm{Tl}_{1} \mathrm{Ba}_{2} \mathrm{Ca}_{2} \mathrm{Cu}_{3} \mathrm{O}_{x}$ (Tl-1223) High Temperature Superconductor Films Synthesized via an Electrodeposited Precursor," Materials Letters, Vol. 39, No. 1, 1999, pp. 5862. http://dx.doi.org/10.1016/S0167-577X(98)00217-1

[18] H. Chou, T. H. Chow, K. K. Wang, Z. M. Chau, H. S. Chen, E. A. Fitzgerald and S. N. Hsu, "Spontaneous Patterning in High Temperature Superconducting Film by Liquid-Gas-Solidification Processing," Applied Physics Letters, Vol. 65, No. 8, 1994, p. 1045. http://dx.doi.org/10.1063/1.112147

[19] A. Goyal, E. D. Specht, D. M. Kroeger, J. E. Tkacyzk, C. L. Briant and J. A. DeLuca, "Crystallization of Colonies of Locally Aligned Grains during Thallination of SprayPyrolyzed $\mathrm{TlBa}_{2} \mathrm{Ca}_{2} \mathrm{Cu}_{3} \mathrm{O}_{x}$ Thick Films," Applied Physics Letters, Vol. 67,1995, p. 2563.

http://dx.doi.org/10.1063/1.114433

[20] L. Perez, M. Aguilar, J. L. Rosas, C. Falcony and M. Jergel, "Two Step Synthesis of $\mathrm{TlBa}_{2} \mathrm{Ca}_{2} \mathrm{Cu}_{3} \mathrm{O}_{\mathrm{x}}$ Films on Ag Substrates by Spray Pyrolysis of Metal-Acetylacetonates," Revista Mexicana de Fisica, 2008.

[21] R. Sugise and M. Hirabayashi, "The Formation Process of a New High- $T_{\mathrm{c}}$ Superconductor, $\mathrm{TlBa}_{2} \mathrm{Ca}_{4} \mathrm{Cu}_{5} \mathrm{O}_{y}$, with Five CuO Layers," Physica C, Vol. 157, No. 1, 1989, pp. 131134. http://dx.doi.org/10.1016/0921-4534(89)90478-4

[22] T. L. Aselage and E. L. Venturini, "Stability of the Tl1223 Phases," Journal of Applied Physics, Vol. 75, No. 2, 1994, p. 1023. http://dx.doi.org/10.1063/1.356509

[23] W. L. Holstein, "Thermodynamics of the Volatilization of Thallium(I) Oxide from $\mathrm{Tl}_{2} \mathrm{O}, \mathrm{Tl}_{4} \mathrm{O}_{3}$, and $\mathrm{Tl}_{2} \mathrm{O}_{3}$," Journal of Physical Chemistry, Vol. 97, No. 16, 1993, pp. 42244230. http://dx.doi.org/10.1021/j100118a046

[24] J. D. O'Connor, "Thallium-Based HTS Thin Films, Processing, Properties and Applications," Applied Physics Letters, Vol. 69, No. 1, 1996, p. 115.

\section{http://dx.doi.org/10.1063/1.118093}

[25] Y. T. Wang, A. M. Hermann, R. N. Bhattacharya and R. D. Blaugher, "The Study of Critical Current Density of Superconducting Thallium Oxide Films from Spray-Deposited Precursors," International Journal of Hydrogen Energy, Vol. 26, No. 12, 2001, pp. 1289-1293. http://dx.doi.org/10.1016/S0360-3199(01)00062-3

[26] W. L. Holstein, "Thermodynamic Considerations for the Vapor Phase Processing of Tl-Ba-Ca-Cu-O Superconductors," Journal of Physical Chemistry, Vol. 97, No. 16, 1993, pp. 4224-4230. http://dx.doi.org/10.1021/j100118a046

[27] J. A. Deluca, P. L. Karas, J. E. Tkaczyk, P. J. Bednarczyk, M. F. Garbauskas, C. L. Briant and D. B. Sorensen, "The Preparation of "1223" Tl-Ca-Ba-Cu-Oxide Superconducting Films via the Reaction of Silver-Containing Spray Deposited Ca-Ba-Cu-Oxide with Thallium Oxide Vapor," Physica C, Vol. 205, No. 1-2, 1993, pp. 21-31. http://dx.doi.org/10.1016/0921-4534(93)90164-L

[28] H. S. Koo, G. C. Tu and T. Y. Tseng, "Preparation and Characterization of Tl-Ba-Ca-Cu-O Superconducting Films by Spray Pyrolysis and Ti-Diffusion Technique," Journal of the American Ceramic Society, Vol. 77, No. 1, 1994, pp. 27-32.

http://dx.doi.org/10.1111/j.1151-2916.1994.tb06953.x

[29] H. S. Koo and T. Y. Tseng, "Promotion of Phase Transformation and Single-Phase Formation in Silver-Doped Tl-Ba-Ca-Cu-O Superconducting Thin Films," Journal of Materials Research, Vol. 14, No. 5, 1999, pp. 1727-1731. http://dx.doi.org/10.1557/JMR.1999.0234

[30] H. K. Singh, A. K. Saxena and O. N. Srivastava, "The Formation and Characterization of Tl Doped Hg-Ba-Ca$\mathrm{Cu}-\mathrm{O}$ Superconducting Films Synthesised through Spray Pyrolysis," Superconductor Science and Technology, Vol. 8, No. 6, 1995, p. 448.

http://dx.doi.org/10.1088/0953-2048/8/6/009

[31] D. Kumar, M. Sharon, R. Pinto, P. R. Apte, S. P. Rai, S. C. Purandare, L. C. Gupta and R. Vijayraghvan, "Large Critical Currents and Improved Epitaxy of Laser Ablated Ag-Doped $\mathrm{YBa}_{2} \mathrm{Cu}_{3} \mathrm{O}_{7-\delta}$ Thin Films," Applied Physics Letters, Vol. 62, No. 26, 1993, p. 3522. http://dx.doi.org/10.1063/1.109014

[32] M. P. Siegal and E. L. Venturini, "Synthesis and Properties of Tl-Ba-Ca-Cu-O Superconductors," Journal of Materials Research, Vol. 11, No. 12, 1997, pp. 2825-2854. http://dx.doi.org/10.1557/JMR.1997.0378

[33] R. S. Liu, "Superconductivity and the Metal-Semiconductor Transition in the Septenary Oxide System, $\left(\mathrm{Tl}_{0.5} \mathrm{~Pb}_{0.5}\right)\left(\mathrm{Ca}_{1-\mathrm{y}} \mathrm{Y}_{\mathrm{y}}\right) \mathrm{Sr}_{2} \mathrm{Cu}_{2} \mathrm{O}_{7-\delta}$," Japanese Journal of Applied Physics, Vol. 28, 1989, p. 334. http://dx.doi.org/10.1143/JJAP.28.334

[34] T. A. Gladstone, J. C. Moore, A. J. Wilkinson and C. R. Grovenor, "Fabrication of Biaxially Textured Ni Substrates and LaNiO/sub 3/Buffer Layers for Tl-1223 Thick Films," IEEE Transactions on Applied Superconductivity, Vol. 9, No. 2, 1999, pp. 2252-2255. http://dx.doi.org/10.1109/77.784918 